\title{
Treatment of complex laryngotracheal stenosis in childhood-experience of a tertiary University Hospital from 2016 to 2019
}

\author{
Melissa Ameloti Gomes Avelino(D, Laís da Silveira Botacin * (D) and Miguel Angel Corrales Coutinho
}

\begin{abstract}
Background: Laryngotracheal stenosis is a major cause of airway obstruction in pediatric age. The correction of such abnormality still remains a challenge, both because of anatomical issues in childhood and also due to the difficulty in having properly trained professionals and adequate hospital facilities. As treatment, many different surgical techniques are offered ranging from endoscopic and less invasive procedures to open surgeries, such as laryngotracheal reconstruction and cricotracheal resection. The treatment for complex laryngotracheal stenosis is considered successful when we have decannulation or resolution of respiratory failure with release from intensive care unit. Eighteen patients who were monitored at the pediatric otorhinolaryngology service between 2016 and 2019 were diagnosed with complex stenosis, with the collection of demographic data, comorbidities, degree of initial stenosis, post-treatment aspect, and whether or not decannulation occurred.
\end{abstract}

Results: Of the eighteen cases, three had congenital stenosis, fourteen had acquired stenosis, and one had mixed stenosis. Ages ranged from 4 months old to 15 years old. Six (33.3\%) underwent endoscopic dilation procedures only, six (33.3\%) underwent laryngotracheoplasty, and five (27.7\%) cricotracheal resections. One patient underwent a slide tracheoplasty. Seven patients (38.8\%) had to undergo more than one type of procedure to improve stenosis. Out of the eighteen patients, three of them were never tracheostomized. Of the remaining fifteen patients, fourteen (93.3\%) were decannulated.

Conclusions: The success rate in decannulation or the resolution of respiratory failure with discharge from the ICU, after the procedures for correcting stenosis in childhood in our service, was $94.4 \%$.

\section{Background}

Laryngotracheal stenosis (LTS) is one of the main causes of airway obstruction in the pediatric age range [1]. Since the improvement of neonatal and pediatric intensive care units (ICUs), acquired subglottic stenosis has come to be considered as the most common form of LTS, with $90 \%$ being related to endotracheal intubation [2], while congenital stenosis would be present in 5\% of patients [1].

\footnotetext{
* Correspondence: lais.s.a@hotmail.com

Hospital das Clínicas da Universidade Federal de Goiás, Primeira Avenida, s/ n, Bairro: Setor Leste Universitário, Goiânia, Goiás 74605-020, Brazil
}

Correcting such abnormality remains a challenge, both due to the anatomical issue in childhood and the difficulty in forming trained staff, as well as adequate hospital facilities. Experienced professionals of different specialties are needed to work with pediatric airway [3].

As far as treatments are concerned, there are several surgical techniques offered, chosen according to the obstruction characteristic of each patient. There are classifications to assist in defining the degree and location of each type of stenosis. The Myer-Cotton (MC) classification is one of them and is used to define the degree of subglottic stenosis (SGS). It varies

\section{Springer Open}

(0) The Author(s). 2021 Open Access This article is licensed under a Creative Commons Attribution 4.0 International License, which permits use, sharing, adaptation, distribution and reproduction in any medium or format, as long as you give appropriate credit to the original author(s) and the source, provide a link to the Creative Commons licence, and indicate if changes were made. The images or other third party material in this article are included in the article's Creative Commons licence, unless indicated otherwise in a credit line to the material. If material is not included in the article's Creative Commons licence and your intended use is not permitted by statutory regulation or exceeds the permitted use, you will need to obtain permission directly from the copyright holder. To view a copy of this licence, visit http://creativecommons.org/licenses/by/4.0/. 
from I to IV according to severity $[1,4]$. In laryngeal web (LW), the degree of stenosis is defined through Cohen's classification, which varies from I to IV. Posterior glottic stenosis is differentiated by the Bogdasarian classification, divided into four types [4].

Most patients with complex stenosis already live with tracheostomy and expect success in the correction so decannulation can occur, which is also a goal shared by the assistant team, although it is not always achieved due to several causes, including failure in surgical correction and comorbidities of each patient [3-5].

The objective of this work was to describe the experience and success rate of a team specialized in pediatric airways in decannulation and/or resolution of respiratory failure in a group of children with complex LTS discharged from the ICU.

\section{Methods}

Survey of complex cases of LTS operated by the same team specialized in pediatric airways, in a tertiary university hospital, in the period from 2016 to 2019, approved by the institution's ethics committee under the number 32091014.6.1001.5078. This team consisted of an ENT with training in pediatric ENT and focus on pediatric airways, a thoracic surgeon, and intensivists. All patients came from the service's outpatient clinic, a reference in the region for monitoring tracheostomized children, or from the ICUs upon request for advice.

Children and adolescents with complex stenosis were included: glottic, subglottic, transglottic and tracheal, congenital, and/or acquired. In the literature, the definition of acute or chronic acquired stenosis is not clear. Here, all stenosis with less than 30 days of evolution were excluded, but we included those patients between 30 and 90 days, which, according to the classification adopted, are not considered acute [6]. Most patients required tracheostomy or ventilatory support since birth or after an event that caused the stenosis.

Patients who did not agree to participate, who had acute stenosis, patients without complex stenosis (grade I or grade II), and those who missed follow-ups or who did not have post-operative follow-ups after at least 6 months, were excluded.

All cases were submitted to flexible and rigid endoscopic examination, performed by the same team, for proper diagnosis. Complex stenosis was defined as follows: grades III and IV MC, III and IV by Cohen, and III and IV by Bogdasarian, which usually have a classic indication for correction through open surgery [4].

Demographic data, comorbidities, and cause of stenosis were also collected: whether congenital or acquired. Imaging was requested only in the case of tracheal stenosis, to rule out the possibility of extrinsic compression.
After this initial assessment and diagnosis, the best technique for correction was defined according to the changes of each patient. Among the techniques adopted we had the endoscopic ones: balloon dilation, associated or not with sickle knife incisions and local corticoid infiltration for acquired subglottic stenosis only, and open techniques: laryngotracheoplasty (LTP) with costal grafts, cricotracheal resection (PCTR), extended cricotracheal resection (E-PCTR), and slide tracheoplasty. Many times, the same patient needed more than one type of procedure.

The routine of this team, except in cases of congenital and grade IV stenosis, is to initially perform an endoscopic dilation procedure, even in cases that will normally require open surgery. However, dilation is only performed a maximum of four to five times, and when there is an improvement after the procedure.

The routine of the service is to perform the procedures in one and a half or double stage, the first of which consists of maintaining the tracheostomy in addition to the nasotracheal tube after surgery. Thus, the tube acts as a mold and for ventilation while the tracheostomy is occluded and works as an alternative safety airway. The tracheostomy is maintained in double stage, the child is ventilated through it in the postoperative period, and a laryngeal mold is used, which can be a piece of a Montgomery, a LT-mold ${ }^{\circ}$, or something that works as stent and later removed by endoscopy. Unfortunately, the LT-Mold ${ }^{\circ}$ is currently not commercially available.

After surgery, the children were followed endoscopically until they were decannulated. In case the child could not be decannulated, another complementary procedure was indicated to correct the stenosis, being chosen individually.

Decannulation was considered a surgical success in this work. In patients without tracheostomy, success was determined by the absence of respiratory failure and discharge from the ICU. We emphasize that surgical success is not characterized by the total correction of laryngotracheal defects.

\section{Results}

Eighteen children were selected for the study, eight females and 10 males, represented in Table 1; three of them had congenital stenosis: a complete tracheal ring and two laryngeal webs. One had mixed stenosis, and the other 14 had acquired stenosis, 13 of them caused after endotracheal intubation and one after surgery for excision of laryngeal papillomatosis.

Of the total number of patients, seven (38.8\%) with acquired stenosis underwent endoscopic procedures (balloon dilation) as the first option for treatment. In this group, two had non-acute stenosis, but between 30 and 90 days of evolution, and were not tracheostomized 
Table 1 Patients with complex laryngotracheal stenosis

\begin{tabular}{|c|c|c|c|c|c|c|c|}
\hline Patients & $\begin{array}{l}\text { Age } \\
\text { and sex }\end{array}$ & Stenosis type & First procedure & $\begin{array}{l}\text { Second } \\
\text { procedure }\end{array}$ & $\begin{array}{l}\text { Third } \\
\text { procedure }\end{array}$ & $\begin{array}{l}\text { Post procedure } \\
\text { stenosis }\end{array}$ & Decanulation \\
\hline 1 & $\begin{array}{l}3 \text { years, } \\
\mathrm{F}\end{array}$ & Laryngeal web III & LTP A & & & No residual & Yes \\
\hline 2 & $\begin{array}{l}2 \text { years, } \\
M\end{array}$ & Laryngeal web IV & LTP AP & & & Posterior synechiae & Yes \\
\hline 3 & $\begin{array}{l}4 \\
\text { months, } \\
\text { F }\end{array}$ & $\begin{array}{l}\text { Complete tracheal ring (long } \\
\text { segment) }\end{array}$ & Slide tracheoplasty & 1 dilation & LTP A & No residual & $\begin{array}{l}\text { Without } \\
\text { tracheostomy }\end{array}$ \\
\hline 4 & $\begin{array}{l}4 \text { years, } \\
M\end{array}$ & Subglottic stenosis III & 5 dilations $+\mathrm{SKI}+\mathrm{Cl}$ & & & $\begin{array}{l}\text { Subglottic stenosis } \\
\text { I }\end{array}$ & Yes \\
\hline 5 & $\begin{array}{l}4 \\
\text { months, } \\
\text { F }\end{array}$ & Subglottic stenosis III & 1 dilation & & & No residual & $\begin{array}{l}\text { Without } \\
\text { tracheostomy }\end{array}$ \\
\hline 6 & $\begin{array}{l}2 \text { years, } \\
M\end{array}$ & Subglottic stenosis III & 3 dilations $+\mathrm{SKI}+\mathrm{Cl}$ & & & $\begin{array}{l}\text { Subglottic stenosis } \\
\mid\end{array}$ & Yes \\
\hline 7 & $\begin{array}{l}13 \text { years, } \\
M\end{array}$ & Subglottic stenosis III & 1 dilations $+\mathrm{SKI}+\mathrm{Cl}$ & & & $\begin{array}{l}\text { Subglottic stenosis } \\
1\end{array}$ & Yes \\
\hline 8 & $\begin{array}{l}1 \text { year, } \\
M\end{array}$ & Subglottic stenosis III & 1 dilations + SKI & & & $\begin{array}{l}\text { Subglottic stenosis } \\
\mid\end{array}$ & Yes \\
\hline 9 & $\begin{array}{l}13 \text { years, } \\
\mathrm{F}\end{array}$ & Subglottic stenosis IV & PCTR & 3 dilations & & $\begin{array}{l}\text { Subglottic stenosis } \\
\mid\end{array}$ & Yes \\
\hline 10 & $\begin{array}{l}4 \text { years, } \\
M\end{array}$ & Subglottic stenosis IV & PCTR & 1 dilation & & $\begin{array}{l}\text { Subglottic stenosis } \\
\mid\end{array}$ & Yes \\
\hline 11 & $\begin{array}{l}3 \text { years, } \\
M\end{array}$ & $\begin{array}{l}\text { Subglottic stenosis III + glottic } \\
\text { posterior (transglottic) }\end{array}$ & LTP AP & $\begin{array}{l}\text { Endoscopic } \\
\text { LTP P }\end{array}$ & & No residual & Yes \\
\hline 12 & $\begin{array}{l}2 \text { years, } \\
\mathrm{F}\end{array}$ & $\begin{array}{l}\text { Subglottic stenosis III + glottic } \\
\text { posterior (transglottic) }\end{array}$ & $\begin{array}{l}6 \text { dilations and } \\
\text { interarythenoid incision }\end{array}$ & LTP P & 1 dilation & No residual & Yes \\
\hline 13 & $\begin{array}{l}3 \text { years, } \\
M\end{array}$ & $\begin{array}{l}\text { Subglottic stenosis III + glottic } \\
\text { posterior (transglottic) }\end{array}$ & E-PCTR & & & No residual & Yes \\
\hline 14 & $\begin{array}{l}8 \\
\text { months, } \\
\text { M }\end{array}$ & $\begin{array}{l}\text { Subglottic stenosis III + low } \\
\text { mobility vocal folds }\end{array}$ & 3 dilations $+\mathrm{SKI}+\mathrm{Cl}$ & & & No residual & $\begin{array}{l}\text { Without } \\
\text { tracheostomy }\end{array}$ \\
\hline 15 & $\begin{array}{l}5 \text { years, } \\
M\end{array}$ & $\begin{array}{l}\text { Subglottic stenosis IV + glottic } \\
\text { posterior (transglottic) }\end{array}$ & E-PCTR posterior graft & 1 dilation & & No residual & No \\
\hline 16 & $\begin{array}{l}2 \text { years, } \\
\mathrm{F}\end{array}$ & $\begin{array}{l}\text { Subglottic stenosis IV + glottic } \\
\text { posterior (transglottic) }\end{array}$ & E-PCTR & & & No residual & Yes \\
\hline 17 & $\begin{array}{l}7 \text { years, } \\
\mathrm{F}\end{array}$ & Posterior glottic stenosis & LTP P & & & No residual & Yes \\
\hline 18 & $\begin{array}{l}15 \text { years, } \\
F\end{array}$ & Posterior glottic stenosis & Endoscopic LTP P & 1 dilation & & $\begin{array}{l}\text { Posterior scar in left } \\
\text { vocal fold }\end{array}$ & Yes \\
\hline
\end{tabular}

F female, $M$ male, LTP A laringotracheoplasty with anterior graft, LTP $P$ laringotracheoplasty with posterior graft, LTP AP laringotracheoplasty with anterior and posterior grafts, $P C T R$ partial cricotracheal reconstruction, E-PCTR extended partial cricotracheal reconstruction, SKI sickle knife incisions, Cl corticoid infiltration

(patients 5 and 14) and the others had chronic stenosis. Among the seven patients, one had a later indication for LTP with posterior costal graft, and a new dilation-patient 12. Among the other 11 patients, five (27.7\%) underwent LTP and five (27.7\%) had PCTR as first procedure. One of the patients underwent a slide tracheoplasty as first procedure because she had a complete long segment tracheal ring.

Among the five patients with isolated grade III MC SGS (Table 1, patients 4-8), all of them underwent only balloon dilations, four were associated with sickle knife incisions and three were also injected with corticosteroids. None of these patients required open interventions to correct the stenosis, with success in decannulation in $100 \%$ of cases. Three patients had SGS MC III associated with posterior glottic stenosis (patients 11-13), and in these cases open procedures were indicated-LTP with costal grafts or extended PCTRassociated or not with dilations before or after open surgery. In the case of patient 11, an endoscopic LTP was also performed to position a new posterior costal graft after the first graft was lost due to local infection. In the case with SGS MC III associated with reduced vocal fold mobility (patient 14), balloon dilations associated with 
sickle knife incisions and corticosteroid infiltration were sufficient to resolve the stenosis.

Four patients had grade IV MC SGS and in two the stenosis extended to the posterior glottic region. In all cases, PCTR was performed, and in cases of transglottic strictures, the extended technique was chosen. In three cases, balloon dilation was required after an open procedure. The only case in which decannulation did not occur was that of patient 15: transglottic stenosis, who underwent extended PCTR, associated with postoperative dilation, but he had many comorbidities.

Two patients had posterior glottic stenosis, one caused by previous surgical trauma and the other by prolonged endotracheal intubation. These patients underwent LTP with a posterior costal graft, which for the first patient it was enough. In the second case, LTP was performed endoscopically, and subsequent balloon dilation was required, with resolution of the condition.

Two other patients had laryngeal web, that is, congenital conditions, with patient 1 having type III (Fig. 1a). He underwent LTP with an anterior costal graft, without the need for other procedures. The other patient had type IV and went through LTP with anterior and posterior costal grafts, without the need for further corrections. The two patients kept the LT-mold ${ }^{\circ}$ in for about 6 weeks.

Patient 3, diagnosed with a complete tracheal ring (long segment), also had laryngomalacia, with no other comorbidity or alterations of large vessels, confirmed by $\mathrm{CT}$ angiography. For this patient, tracheostomy was contraindicated and a slide tracheoplasty was done. In the procedure, extracorporeal membrane oxygenation (ECMO) was required, and teams of thoracic and cardiac surgery were mobilized, in addition to the otolaryngology and neonatal ICU team. Subsequently, we performed balloon dilation, as she presented stenosis in the proximal trachea (upper suture region), which did not respond after two dilations, and then LTP with an anterior costal graft was indicated to increase the caliber in this narrowed region of the proximal trachea, which was successful in the post-operative period and as a result, the patient was discharged from the hospital.

Seven out of 18 patients (38.8\%) needed to perform more than one type of procedure to obtain satisfactory results for the correction of LTS. These procedures ranged from open surgeries to balloon dilations, the latter being the most performed as complementation of open surgery post-operative period.

Of the total number of patients, only three were never tracheostomized: patients 3, 5, and 14. One of them had a long segment tracheal ring-congenital malformation-and two of them had acquired grade III stenosis and were less than 4 months old. All of them showed improvement in respiratory failure after treatment and were discharged. Among the remaining 15 patients, 14 (93.3\%) were decannulated, and one decannulation was unsuccessful. This patient had such difficulty due to dysphagia and is still being followed up as an outpatient.

\section{Discussion}

The correction of LTS remains a challenge, especially in the pediatric population. Due to the lack of trained staff for early recognition and treatment of this stenosis, often the only management that the patient receives is the making of the tracheostomy. It is estimated, according

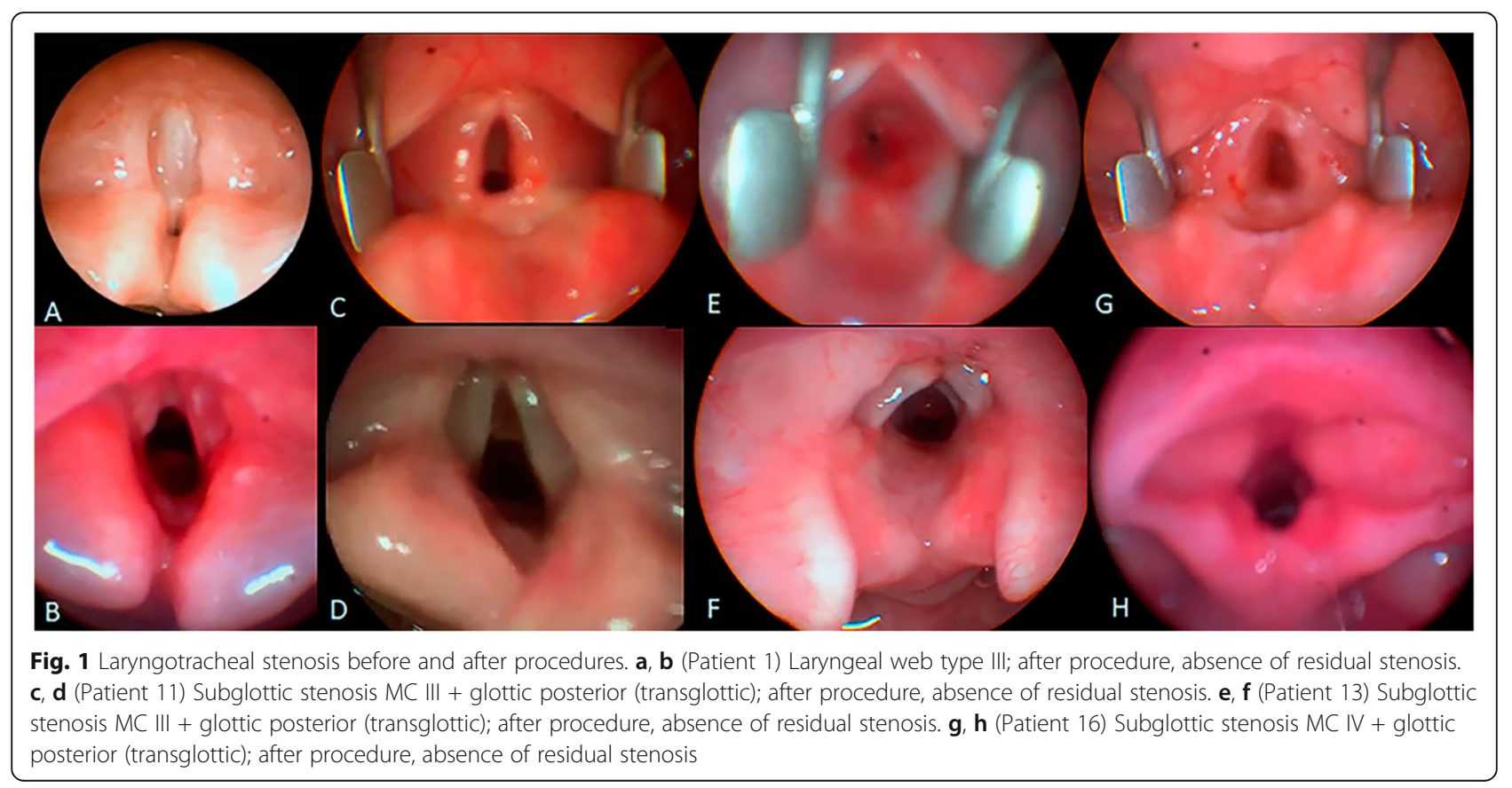


to the international literature, that $0.5-2 \%$ of children submitted to intubation and mechanical ventilation in the ICU evolves to tracheostomy [7]. In addition to not treating the cause of the stenosis, the tracheostomy ends up generating changes in the family dynamics and reducing the quality of life of the patient and family [7]. Moreover, it can evolve into complications such as stenosis, suprastomal collapse, granulomas, cannula obstruction, and even death, especially outside a hospital setting $[4,7]$. Thus, the ideal course of action would be that in ICU settings, after two extubation failures, an airway endoscopy should be performed and a diagnosis made before a tracheostomy, or as soon as possible, according to Avelino et al. [7].

Among methods for treatment of stenosis, we have those performed by endoscopy, more common since the 1960s [8], including the technique of dilation with vascular balloons (balloon laryngoplasty), first described by Durden and Sobol, in 2007 [9], which was then popularized, showing good results, even in cases of acquired complex stenosis [10]. In some cases, balloon laryngoplasty prevents tracheostomy, especially in younger children, reaching a rate of $100 \%$ resolution of the stenosis $[11,12]$. It has the advantage of applying force radially, reducing glottic trauma and the chance of restenosis, and therefore, reducing complications [13]. However, there are still no studies comparing the different types of dilation, and consequently, the superiority of the use of the balloon in relation to candles, tubes, or others [14] cannot be asserted.

Compared to open procedures, endoscopic dilations have less morbidity, but sometimes, multiple procedures are necessary [9]. Endoscopic balloon dilation has the possibility to reduce the need for open surgery by up to $80 \%$ in cases of SGS [13]. Previous studies have shown a $39 \%$ success rate in cases of chronic stenosis treated with balloon dilation, as described by Avelino et.al [6].. In this study, unlike our previous study, we had a success rate of $80 \%$ in cases of dilation as an initial procedure for chronic stenosis. These patients had acquired grade III stenosis (MC III), except for patient 12, who had acquired transglottic stenosis, which was exactly what led him to an open procedure. In case 12, a previous dilation was performed, as this could positively interfere, facilitating the open approach [10]. The degree of stenosis and the characteristics of the scar tissue can interfere in the result [6]. In cases 5 and 14, non-tracheostomized patients, in which the stenosis was treated with balloon dilation during an earlier phase, between 30 and 90 days, the success was $100 \%$, corroborating with the results of other studies $[6,11,12]$. In most cases, sickle knife incisions and intralesional corticosteroids were associated. In cases of congenital stenosis, in which LTS is usually confirmed due to a reduction in the caliber of cartilage structures or other structural changes, dilation is not indicated and may even worsen the initial stenosis, with open surgery being indicated in these cases [15]. An open approach is not contraindicated as the recommendation for dilation as the initial treatment for stenosis, even the most complex ones. It is complementary, in case the first one does not yield the expected outcome $[6,9]$.

LTP with anterior graft has a success rate in the literature that exceeds $90 \%$ [16], and today it is mainly the one performed in patients with a lower degree of stenosis or patients who have failed endoscopic treatment or who have suprastomal collapse [13], but we did not include this less complex stenosis in this study. LTP with posterior graft is indicated in patients with more severe SGS, in posterior glottic stenosis, and in the reduction of vocal fold mobility [13]. In our cases, LTP with posterior graft was performed in children who had associated glottic alteration, and decannulation was successful in 100\% of cases.

Two patients underwent LTP with anterior and posterior grafts. Patient 2 had LW type IV and decannulation was successful, despite maintaining a small anterior synechiae. Patient 11 had acquired transglottic (Fig. 1c) stenosis and in addition to this open procedure, he had a new LTP with posterior costal graft, performed by endoscopy, after loss of the first posterior graft due to an infection seven days after the operation. In this case, the patient had a successful decannulation after the second procedure. In the first patient (patient 2), we used the LT-mold ${ }^{\circ}$, like in the other case of LW. It followed the principles of mucosal approximation after cartilage remodeling and atraumatic stenting and this might have accounted for less scarring and favorable voice results [17].

Another method is PCTR, in which the stenosis segment is removed and airway reconstruction is performed $[13,18]$. This procedure is more challenging than LTP and has the double risk of injuring the recurrent laryngeal nerves (RNLs) or that of anastomotic dehiscence. On the other hand, this approach minimizes the problems of wound-healing encountered with costal cartilage grafts and stenting in LTP. When PCTR is combined with an additional open airway procedure, it is referred to as an extended PCTR. This procedure is suggested for patients presenting LTS with glottic involvement. Glottic involvement may present itself as posterior glottic stenosis with possible cricoarytenoid joint fixation, cicatricial fusion of the vocal cords, and transglottic cicatricial stenosis, or as a completely distorted larynx due to previous failed Laryngotracheal reconstructions (LTRs). EPCTR consists of a posterior cricoid split with costal cartilage graft, resection of subglottic stenosis, and stenting for 4-6 weeks. PCTR was chosen for two patients and E-PCTR in three cases. In PCTR patients, we had $100 \%$ decannulation, while in E-PCTR, we obtained 
Table 2 Associated comorbidities

\begin{tabular}{ll}
\hline Patient $\mathbf{2}$ & Genetic syndrome \\
\hline Patient 8 & Extreme prematurity + gastrostomy + neuropsychomotor delay \\
Patient 13 & Cardiopathy \\
Patient 14 & Pneumopathy - stenosis after pneumonia \\
Patient 15 & Cardiopathy + cleft lip + triangular epiglottis + supernumerary bronchus \\
Patient 16 & Developmental delay after meningoencephalitis \\
\hline
\end{tabular}

successful decannulation in two of three patients (66\%). In a series published by Monnier [18], the rate of decannulation was $100 \%$ in cases that underwent PCTR and $90 \%$ for those who underwent E-PCTR. In case 15, decannulation was not possible, he was an extremely premature baby and had neurologic impairment. This patient after E-PCTR, despite the recovery of the laryngeal lumen, maintained dysphagia with videodeglutogram showing aspiration, so the cannula was kept to avoid it. He maintains a $3.5-\mathrm{mm}$ tracheostomy cannula and a speech valve to compensate for dysphagia, but the gastrostomy has been removed and he continues with speech therapy, and his voice has improved considerably.

Some factors are already recognized as difficult to decannulation, namely, degree of stenosis: complex stenosis would have less chance of decannulation [19]; if the procedure is done in single stage, hybrid (one and a half) or in double stages: it is known that procedures done in single stage have a better rate of decannulation. However, Smith et al. [20] demonstrated that the success rate in procedures performed in a hybrid way is close to those performed in a single stage. In this study, the patients underwent the procedures in double stages or in one and a half stage, though double stages were more commonly performed. The only non-decannulated patient had a procedure performed in double stages. Another factor is the presence and type of comorbidities. Schweiger et al. [5] demonstrated in a recent study that neurological and pulmonary comorbidities led to a lower chance of decannulation, as well as the presence of several comorbidities in the same patient [5]. According to Monnier [4], the association between comorbidities and the degree of glottic dysfunction in SGS leads to a worse prognosis after PCTR: if the patient has only SGS, MC grades III and IV, the decannulation rate is $97 \%$. If the stenosis is associated with comorbidities or glottic involvement, it drops to $93 \%$ and $89 \%$, respectively. In cases of SGS with glottic involvement and comorbidities, the decannulation rate drops to $64 \%$ [4]. Among the 18 patients in this study, $33.3 \%$ had some comorbidity, as shown in Table 2. The only non-decannulated patient has a history of extreme prematurity, delayed neuropsychomotor development, and gastrostomy.

The series of cases presented shows the experience of a tertiary university hospital, which despite having skilled surgeons in managing airways, difficulties inherent to the public health system for the monitoring and treatment of LTS can arise, causing improvements in the quality of life of the child and his family to be postponed. In spite of it all, our success rate for decannulation was $93.3 \%$, and if associated with resolution of respiratory failure and discharge from the ICU, the final resolution was $94.4 \%$, above that described in the literature: $86 \%$, according to Maunsell et al. [3], and 88\% according to Fiz et al. [1]. We believe that our high success rate may be related to a lower rate of comorbidities in the selected children, and when they were present, they were less severe. None of the patients had severe neurological or pulmonary changes, but in our opinion, these factors should always be considered in relation to the expectation of surgical success.

Our study demonstrates a good feasibility in performing complex surgeries, even with all the difficulties of our public health system, besides reinforcing that sometimes carrying out procedures in one and a half and/or double stages is reassuring to the entire team involved, especially in the post-operative periods in the ICUs. This was not a factor that limited our surgical success. Single stage surgeries, which are widely recommended in first world countries, could even put our patients at greater risk, given the Brazilian reality, with fewer professionals involved in the care of patients in the ICUs.

\section{Conclusions}

Our study showed a $94.4 \%$ success rate in decannulation or resolution of respiratory failure, after surgical treatment of complexes LTS, rates slightly higher than other studies, probably due to the profile of few comorbidities in these children.

\section{Abbreviations}

LTS: Laryngotracheal stenosis; ICUs: Intensive care units; MC: Myer-Cotton; SGS: Subglottic stenosis; LW: Laryngeal web; LTP: Laryngotracheoplasty; PCTR: Cricotracheal resection; E-PCTR: Extended cricotracheal resection; ECMO: Extracorporeal membrane oxygenation; LTRs: Laryngotracheal reconstructions 


\section{Acknowledgements}

- We thank Professor Philippe Monnier for his generous teaching and donation of LT-Molds ${ }^{\oplus}$.

- The study authors are grateful to the entire team that participated in the care of each patient presented in this article.

\section{Authors' contributions}

All authors have read and approved the manuscript. MAGA made substantial contributions to the conception, the data acquisition and interpretation, substantively revised, approved the submitted version, and have agreed both to be personally accountable for the author's own contributions and to ensure that questions related to the accuracy or integrity of any part of the work, even ones in which the author was not personally involved, are appropriately investigated, resolved, and the resolution documented in the literature. LSB made contributions to the conception, the data acquisition and interpretation, revised, approved the submitted version, and have agreed both to be personally accountable for the author's own contributions and to ensure that questions related to the accuracy or integrity of any part of the work, even ones in which the author was not personally involved, are appropriately investigated, resolved, and the resolution documented in the literature. MACC made substantial contributions to data acquisition and interpretation, approved the submitted version, and have agreed both to be personally accountable for the author's own contributions and to ensure that questions related to the accuracy or integrity of any part of the work, even ones in which the author was not personally involved, are appropriately investigated, resolved, and the resolution documented in the literature.

\section{Funding}

Author funding

\section{Availability of data and materials}

The data that support the findings of this study are available from medical records in each institution, but restrictions apply to the availability of these data, which were used under license for the current study, and so are not publicly available. Data are however available from the authors upon reasonable request and with permission of the institutions.

\section{Ethics approval and consent to participate}

Approved by the institution's ethics committee under the number 32091014.6.1001.5078. A written informed consent was obtained from a parent or legal guardian of participants under 16 years old.

\section{Consent for publication}

Consent to publish was obtained from the parents or legal guardian.

\section{Competing interests}

The authors declare that they have no competing interests.

Received: 11 September 2020 Accepted: 9 December 2020

Published online: 14 January 2021

\section{References}

1. Fiz I, Monnier P, Koelmel JC, Di Dio D, Torre M, Fiz F, et al. Implementation of the European Laryngological Society classification for pediatric benign laryngotracheal stenosis: a multicentric study. Eur Arch Otorhinolaryngol. 2019;276(3):785-9.

2. Holinger $\mathrm{PH}$, Kutnick SL, Schild JA, Holinger LD. Subglottic stenosis in infants and children. Ann Otol Rhinol Laryngol. 1976;85(5):591-9.

3. Maunsell $R$, Lacerda NS, Prata L, Brandão M. Pediatric airway reconstruction: results after implementation of an airway team in Brazil. Braz J Otorhinolaryngol. 2020;86(2):157-64.

4. Monnier P. Pediatric Airway Surgery. Berlin, Heidelberg: Springer Berlin Heidelberg; 2011. http://link.springer.com/10.1007/978-3-642-13535-4.

5. Schweiger C, Manica D, Lubianca Neto JF, Sekine L, Krumenauer R, Caixeta $J A$, et al. Determinants of successful tracheostomy decannulation in children: a multicentric cohort study. J Laryngol Otol. 2020;134(1):63-7.

6. Avelino M, Maunsell $R$, Jubé WI. Predicting outcomes of balloon laryngoplasty in children with subglottic stenosis. Int J Pediatr Otorhinolaryngol. 2015;79(4):532-6.
7. Avelino MAG, Maunsell R, Valera FCP, Lubianca Neto JF, Schweiger C, Miura $\mathrm{CS}$, et al. First clinical consensus and national recommendations on tracheostomized children of the Brazilian Academy of Pediatric Otorhinolaryngology (ABOPe) and Brazilian Society of Pediatrics (SBP). Braz J Otorhinolaryngol. 2017:83(5):498-506.

8. Rutter MJ, Cohen AP, de Alarcon A. Endoscopic airway management in children. Curr Opin Otolaryngol Head Neck Surg. 2008;16(6):525-9.

9. Durden F, Sobol SE. Balloon laryngoplasty as a primary treatment for subglottic stenosis. Arch Otolaryngol Head Neck Surg. 2007;133(8):772.

10. Guarisco JL, Yang CJ. Balloon dilation in the management of severe airway stenosis in children and adolescents. J Pediatr Surg. 2013;48(8):1676-81.

11. Avelino M, Fernandes E. Balloon laryngoplasty for subglottic stenosis caused by orotracheal intubation at a tertiary care pediatric hospital. Int Arch Otorhinolaryngol. 2013;18(01):039-42.

12. Schweiger C, Smith MM, Kuhl G, Manica D, Marostica PJC. Laringoplastia com balão em crianças com estenose subglótica em evolução: experiência de um hospital terciário. Braz. j. otorhinolaryngol. (Impr.) [Internet]. 2011; 77 (6): 711-715. http://www.scielo.br/scielo.php?script=sci_arttext\&pid=\$180886942011000600006\&lng=es. https://doi.org/https://doi.org/10.1590/S180886942011000600006.

13. Jefferson ND, Cohen AP, Rutter MJ. Subglottic stenosis. Semin Pediatr Surg. 2016:25(3):138-43.

14. Chueng K, Chadha NK. Primary dilatation as a treatment for pediatric laryngotracheal stenosis: a systematic review. Int J Pediatr Otorhinolaryngol. 2013;77(5):623-8.

15. Thompson JW, Vieira F, Rutter MJ. Management of the difficult airway: a handbook for surgeons. London: JP Medical; 2016.

16. Gustafson LM, Hartley BEJ, Liu JH, Link DT, Chadwell J, Koebbe C, et al. Single-stage laryngotracheal reconstruction in children: a review of 200 cases. Otolaryngol Head Neck Surg. 2000;123(4):430-4.

17. Avelino MA, Pazinatto DB, Rodrigues SO, Maunsell R. Congenital laryngeal webs: from diagnosis to surgical outcomes. Braz J Otorhinolaryngol. 2020 https://doi.org/https://doi.org/10.1016/j.bjorl.2020.06.018.

18. Monnier P. Partial cricotracheal resection and extended cricotracheal resection for pediatric laryngotracheal stenosis. Thoracic Surgery Clinics. 2018;28(2):177-87

19. Padia R, Sjogren P, Smith M, Muntz H, Stoddard G, Meier J, et al. Int J Pediatr Otorhinolaryngol. 2018;108:168-74.

20. Smith DF, de Alarcon A, Jefferson ND, Tabangin ME, Rutter MJ, Cotton RT, et al. Short- versus long-term stenting in children with subglottic stenosis undergoing laryngotracheal reconstruction. Otolaryngol Head Neck Surg. 2018;158(2):375-8

\section{Publisher's Note}

Springer Nature remains neutral with regard to jurisdictional claims in published maps and institutional affiliations.

\section{Submit your manuscript to a SpringerOpen ${ }^{\circ}$ journal and benefit from:}

- Convenient online submission

- Rigorous peer review

- Open access: articles freely available online

High visibility within the field

- Retaining the copyright to your article

Submit your next manuscript at $\boldsymbol{\nabla}$ springeropen.com 